\title{
Dielectric Properties of Compounds Creating Dual-Frequency Nematic Liquid Crystals
}

\begin{abstract}
M. Mrukiewicz ${ }^{a, *}$, P. Perkowski ${ }^{a}$, K. Garbat ${ }^{b}$, R. DAzBrowski ${ }^{b}$ And J. PARkA ${ }^{a}$
${ }^{a}$ Institute of Applied Physics, Military University of Technology, S. Kaliskiego 2, 00-908 Warsaw, Poland

${ }^{b}$ Institute of Chemistry, Military University of Technology, S. Kaliskiego 2, 00-908 Warsaw, Poland

In this paper we report how dielectric spectroscopy can help in creating of dual-frequency nematic liquid crystals. Dual-frequency nematic liquid crystals is new class of liquid crystal materials. Such mixture is usually formed by a combination of many components (even more than 10), which can be split into two groups: molecules having large transverse dipole moment and molecules with a large longitudinal dipole moment. The behavior of a base (parent) mixture, functional admixtures and final dual-frequency nematic liquid crystals mixture is investigated by dielectric spectroscopy in wide frequency $(100 \mathrm{~Hz}-10 \mathrm{MHz})$ and temperature ranges. This allows us to find out why the dual-frequency liquid crystal has an important feature: positive and negative dielectric anisotropy at different frequencies. We present parameters of molecular motions around short (S-mode) and long (L-mode) molecular axes observed in investigated materials and discuss how the creation of final dual-frequency nematic liquid crystals mixture can modify molecular relaxations.
\end{abstract}

DOI: 10.12693 /APhysPolA.124.940

PACS: 77.22.Gm, 77.84.Nh, 61.30.-v

\section{Introduction}

Nematic liquid crystals are very interesting materials from applications point of view, because the liquid crystals (LC) directors can be oriented by electric field. It causes changing of optical properties from transparent to non-transparent state (between crossed polarizers). However the disadvantage in the most liquid crystals displays is long turn-off relaxation process. Turn-off process is driven by elastic properties of nematic medium and, simultaneously, it is slowed down by its own viscosity. This is due to the fact that only turn-on process can be accelerated by increase of external voltage. It is why turn-on process is sufficiently fast. Solution of this problem seems to be dual-frequency nematic liquid crystals (DFNLCs).

The story of these materials started in the eighties $[1,2]$. DFNLCs generally possess positive dielectric anisotropy at low frequencies, but above so-called cross-over frequency $f_{\mathrm{C}}$ they have negative dielectric anisotropy [3-7]. Thus, by switching the frequency from below to above the cross-over frequency, the direction of average molecular orientation (director) can be changed. Applying a low frequency electric signal to a planar oriented cell, where a director of liquid crystal molecules is parallel to the electrode surface, the orientation change to position where the director is perpendicular to the surface. This effect is driven by a force momentum induced by interaction of the electric field and a medium exhibiting positive dielectric anisotropy $(\Delta \varepsilon>0)$. On the other hand, when we put the high frequency electric signal, which should be higher than cross-over frequency, cell goes back to planar orientation. This process is driven by

*corresponding author; e-mail: mmrukiewicz@wat.edu.pl a force momentum due to negative dielectric anisotropy $(\Delta \varepsilon<0)[8,9]$. This two-way driving of LC molecules has been utilized in nematic liquid crystals to improve their switching speed, especially in devices where a large cell-gap is required, since the decay-time of a nematic LC increases proportionally to the square of the cell-gap. From application point of view the most important parameter in DFNLC is cross-over frequency [3]. In this paper we investigate how molecular rotations (around long and short molecular axes) observed in compounds creating DFNLC modify in final DFNLC mixture. To answer this question the base mixture (with negative dielectric anisotropy $\Delta \varepsilon<0$ ), both admixtures: 1 and A2 (with $\Delta \varepsilon>0)$ and final DFNLC were studied by dielectric spectroscopy.

In dielectric spectroscopy we can observe relaxation process of molecules creating dual-frequency liquid crystal mixture. Relaxation process can be described by well-known Debye equations (1) and (2):

$$
\begin{aligned}
& \varepsilon^{\prime}(f)=\varepsilon_{\infty}+\frac{\varepsilon_{\mathrm{S}}-\varepsilon_{\infty}}{1+\frac{f^{2}}{f_{\mathrm{R}}^{2}}}, \\
& \varepsilon^{\prime \prime}(f)=\varepsilon_{\infty}+\frac{\varepsilon_{\mathrm{S}}-\varepsilon_{\infty}}{1+\frac{f^{2}}{f_{\mathrm{R}}^{2}}} \frac{f}{f_{\mathrm{R}}} .
\end{aligned}
$$

The real $\varepsilon^{\prime}(f)$ and imaginary $\varepsilon^{\prime \prime}(f)$ part of electric permittivity depends on rotation around long (L-mode) and short (S-mode) molecular axes. Relaxation frequency $f_{\mathrm{R}}$ is a molecular parameter describing molecular dynamic. Every modes: L-mode and S-mode possess their own characteristic relaxation frequency. Above their relaxation frequencies, S-mode and L-mode rotations do not give any contribution into dielectric response of the sample. In dielectric spectroscopy $f_{\mathrm{R}}$ is defined as point of inflection for the dispersion $\left(\varepsilon^{\prime}(f)\right)$ curve. Furthermore on absorption spectra can be obtained from maximum value of imaginary part of electric permittivity $\left(\varepsilon^{\prime \prime}(f)\right)$. 
Values of $\varepsilon_{S}$ and $\varepsilon_{\infty}$ stand for the static and high frequency permittivity limits.

The relaxation frequency has an activation character and can be expressed by the Arrhenius formula (3):

$$
f_{\mathrm{R}}=f_{\infty} \exp (-\Delta E / R T),
$$

where $\Delta E$ is activation energy, $f_{\infty}-$ high temperature limit of relaxation frequency.

Calculated relaxation frequency and activation energy of the base mixture, admixtures and final dual-frequency mixture allows us to look for the relationships between the molecular structures, molecular dynamics and the dielectric properties of the substances.

\section{Investigated materials}

Example of new dual-frequency nematic liquid crystal is W1832 A [8]. It is prepared by the base mixture W1832 doped with $20 \mathrm{wt} \%$ of two components 1 and 2 [10]. 1 has two carbon atoms in terminal chain $(n=2)$ while 2 possesses five carbon atoms in terminal chain (Table I, right). From molecular point of view the base mixture is composed of molecules (Table I, left - only one example of typical molecule building W1832 base mixture) with strong transverse dipole moment $\mu_{\perp}$, while longitudinal one $\mu_{\|}$almost does not exist. The dipole moments were calculated (for one molecule which built base mixture) using molecular modeling software Hyper Chem 7.5 [8]. The main source of dipole moments in base mixture are fluorine atoms laterally attached to the rigid molecular core.

TABLE I

Template molecular structures and dipole moments of the compounds constituting DFNLC W1832A.

\begin{tabular}{c|l}
\hline \hline Base mixture (W1832A) & \multicolumn{1}{|c}{ Admixtures } \\
\hline $\begin{array}{l}\text { Large perpendicular compo- } \\
\text { nent of dipole moment } \mu_{\perp}\end{array}$ & $\begin{array}{l}\text { Large parallel component of } \\
\text { dipole moment } \mu_{\|}\end{array}$ \\
\hline$\mu_{\mathrm{B} \perp}=3.66 \mathrm{D}, \mu_{\mathrm{B} \|}=0.87 \mathrm{D}$ & $1: \mu_{1 \perp}=0.67 \mathrm{D}$
\end{tabular}

On the other hand, both admixtures consist of molecules which have strong $\mu_{\|}$dipole moment (Table I, right). The main source of dipole moments in admixtures is NCS group and electronegative fluorine atoms attached at the end of the rigid molecular core. Moreover, admixtures have excellent solubility in the majority of typical nematic mixtures because of their low melting enthalpy.

\section{Experiment}

Substances were placed into cells with gold electrodes. Cells were prepared in our laboratory. We use two types of cells: planar (HG) and homeotropic (HT) orientation, to obtain electric permittivities in perpendicular $\left(\varepsilon_{\perp}\right)$ and parallel $\left(\varepsilon_{\|}\right)$direction, respectively. Cells walls were covered by rubbed polyimides SE 130 and SE 1211 to obtain proper HG and HT orientations, respectively. Due to gold electrodes we can avoid the problem with high frequency losses [11, 12]. Cells thicknesses were around $5 \mu \mathrm{m}$. The low resistivity wires were soldered into the cell, with an ultrasonic USS-9200 unit. The wires should be as short as possible to reduce an inductance effect [13]. Measurements were performed by Hewlett Packard 4192A impedance analyzer, in a wide frequency range from $100 \mathrm{~Hz}$ to $10 \mathrm{MHz}$ with weak $\mathrm{AC}$ measuring field $(0.1 \mathrm{~V})$ to avoid nonlinear responses. Temperature was controlled by Linkam TMS 92 and hot stage Linkam TMSH 600 with an accuracy of $0.1^{\circ} \mathrm{C}$. The measurements were taken every $0.5^{\circ} \mathrm{C}$ with rate $0.3^{\circ} \mathrm{C} / \mathrm{min}$. To perform measurements below the room temperature custom-made cooling system with dry ice was used. The cells were filled by capillary effect in an isotropic phase a few degrees above the clearing temperature (for admixtures cell was filled in nematic phase). Capacity $(C)$ and conductance $(G)$ was measured (in parallel equivalent circuit) and from these parameters real $\left(\varepsilon^{\prime}\right)$ and imaginary $\left(\varepsilon^{\prime \prime}\right)$ parts of electric permittivity were calculated, using well known procedures [8].

\section{Results and discussion}

In Fig. 1 the real parts of electric permittivity of the base mixture W1832 in the cooling cycle are presented as function of temperature for both HG and HT cells $\left(\varepsilon_{\perp}^{\prime}\right.$ and $\left.\varepsilon_{\|}^{\prime}\right)$. Temperature of phase transition between isotropic and nematic phase (clearing temperature) is around $42{ }^{\circ} \mathrm{C}$. In the isotropic phase results for planar (HG) and homeotropic cells (HT) are similar. No clear dispersion can be seen but measured values are slightly higher for lower temperatures. This is caused by the density increase. At temperatures below $42^{\circ} \mathrm{C}$ we observe temperature dependence of electric permittivity. Obtained results show that the base mixture has negative dielectric anisotropy $\left(\varepsilon_{\perp}^{\prime}\right.$ is higher than $\left.\varepsilon_{\|}^{\prime}\right)$. For $25^{\circ} \mathrm{C}$, at $1 \mathrm{kHz}$, the dielectric anisotropy is $\Delta \varepsilon=-2.28$. For room temperatures one does not observe any clear dispersion for both $\varepsilon_{\perp}^{\prime}$ and $\varepsilon_{\|}^{\prime}$ permittivities. For lower temperatures (below $-10^{\circ} \mathrm{C}$ ) electric permittivity goes continuously down because the rotation around long molecular axis (L-mode) becomes slower and slower [8, 9]. Relaxation frequency of the L-mode drops with decreasing temperature. Small molecules constituting the base mixture W1832 possess a large perpendicular component of dipole moment $\left(\mu_{\perp}\right)$. In base mixture we do not observe rotation around short molecular axis (S-mode). It is worth to underline that L-mode can be observed in both $\mathrm{HG}$ and HT orientation. Of course, in HG cell the magnitude of L-mode is higher. In HT cell L-mode is detected due to imperfect homeotropic orientation [8]. 


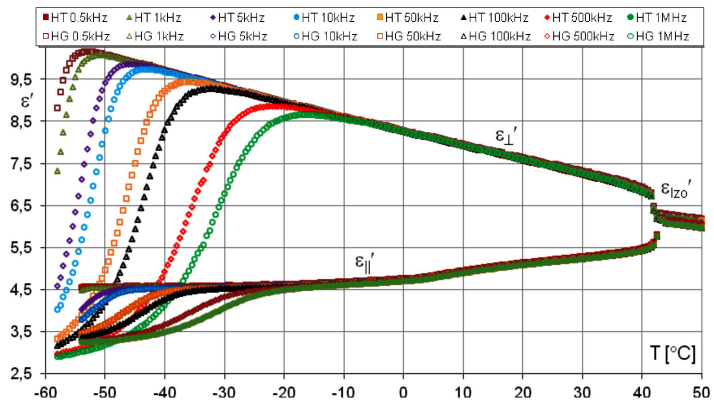

Fig. 1. Real part of electric permittivity $\left(\varepsilon^{\prime}\right)$ measured at frequencies $f$ of $0.5,1,5,10,50,100,500,1000$, $3000 \mathrm{kHz}$ at the full temperature domain upon a cooling cycle for the base mixture (W1832).

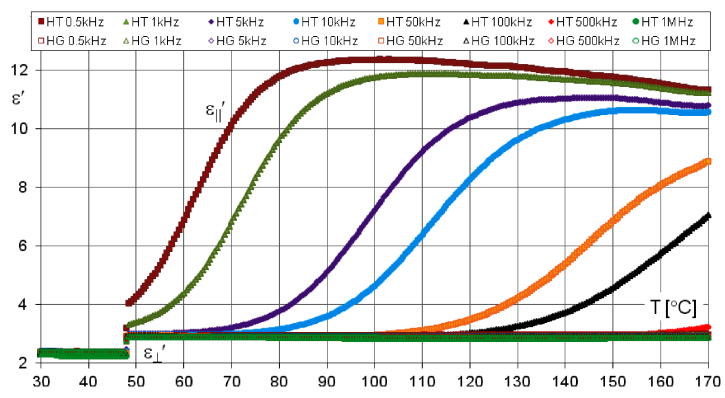

Fig. 2. Real part of electric permittivity $\left(\varepsilon^{\prime}\right)$ measured at frequencies $f$ of $0.5,1,5,10,50,100,500,1000$, $3000 \mathrm{kHz}$ versus temperature upon a cooling cycle for component A1.

We also measured by dielectric spectroscopy both admixtures 1 and 2 [8] which were added to get DFNLC mixture. Each component has large positive dielectric anisotropy. The results for the real part of electric permittivity for both HG and HT orientations are presented below (Figs. 2 and 3) for compounds with $n=2$ and 5 carbon atoms in terminal chain, respectively. For $100^{\circ} \mathrm{C}$ they exhibit $\Delta \varepsilon_{1}=9.5$ and $\Delta \varepsilon_{2}=8.4$ at $1 \mathrm{kHz}$, re-

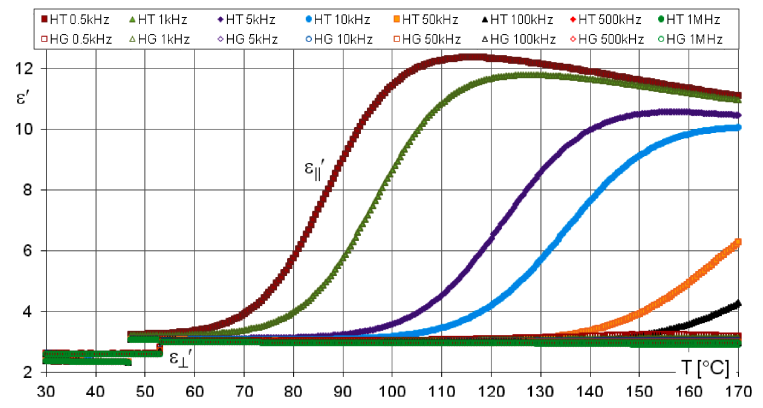

Fig. 3. Real part of electric permittivity $\left(\varepsilon^{\prime}\right)$ measured at frequencies $f$ of $0.5,1,5,10,50,100,500,1000$, $3000 \mathrm{kHz}$ versus temperature upon a cooling cycle for component A2. spectively. Both compounds show nematic phase in a very broad temperature range - clearing temperatures are higher than $350^{\circ} \mathrm{C}$. We know it from differential scanning calorimetry (DSC) measurements. Results at higher temperatures than $170^{\circ} \mathrm{C}$ cannot be measured in dielectric spectroscopy because of technical reasons, related to limited range of temperature used in our measuring system. Such high clearing temperature results from a large molecular weight. Furthermore, the phase transition to the crystalline phase $\left(c a .48^{\circ} \mathrm{C}\right)$ is much higher than in the base mixture (below $-60^{\circ} \mathrm{C}$ ) from the same reason. High value of electric permittivity in $\mathrm{HT}$ cell comes from S-mode (rotation around short molecular axis) [8, 9]. This mode in HG cell is not observed.

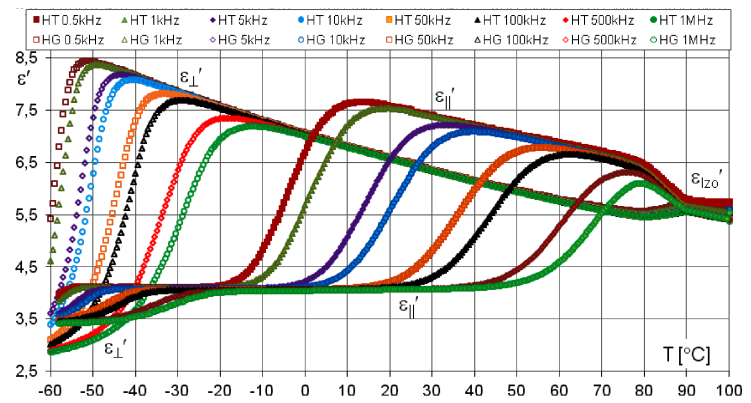

Fig. 4. Real part of electric permittivity $\left(\varepsilon^{\prime}\right)$ measured at frequencies $f$ of $0.5,1,5,10,50,100,500,1000,3000$ $\mathrm{kHz}$ at the full temperature domain upon a cooling cycle for DFNLC [8].

Finally prepared DFNLC mixture (W1832) was composed by the base mixture (W1832) and both admixtures 1 and A2 [8]. From dielectric spectroscopy point of view it has positive and negative dielectric anisotropy in a specific frequency domain (Fig. 4). For example, for room temperature $\left(30^{\circ} \mathrm{C}\right)$ dielectric anisotropy is positive $(\Delta \varepsilon=1.1)$ at frequency $1 \mathrm{kHz}$, while for the same temperature, at frequency $500 \mathrm{kHz}$, it is negative $(\Delta \varepsilon=-2.3)$. Phase transition is at $90^{\circ} \mathrm{C}$ and continues to $80^{\circ} \mathrm{C}$, where nematic phase is well built. S-molecular motion gives contribution into dielectric properties for investigated mixture in $\mathrm{HT}$ cell $\left(\varepsilon_{\|}^{\prime}\right)$ under $80^{\circ} \mathrm{C}$ until $-20^{\circ} \mathrm{C}$. However at this temperature the values of $\varepsilon_{\|}^{\prime}$ and $\varepsilon_{\perp}^{\prime}$ start to drop for the same frequency and temperature range. It is related to the L-mode, which is practically suppressed at $-60{ }^{\circ} \mathrm{C}$. This material in $-70^{\circ} \mathrm{C}$ is still the nematic liquid crystal. It is worth to underline that exactly the same effect at the same temperatures is seen in Fig. 1 for base mixture.

We investigated how the creation of final mixture (W1832 ) can modify the relaxation frequencies observed in base mixture (W1832) and heavy four-ring admixtures (A). From dispersion and absorption spectra (Figs. 5, 6) we noticed that relaxation frequencies are different for DFNLC mixture and its components. What is important, the dielectric strength $\delta \varepsilon$ of both observed modes is lower in DFNLC mixture than in its 


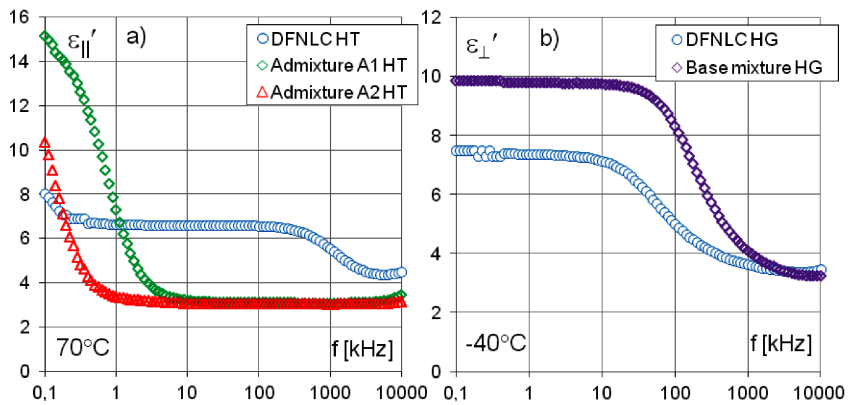

Fig. 5. Dispersion of real part of electric permittivity $\varepsilon^{\prime}$ collected for: (a) DFNLC and admixtures in HT cell. Dielectric strength of S-mode visible in HT cell is higher for admixtures $\left(\delta \varepsilon_{\mathrm{SA} 1}=13.0, \delta \varepsilon_{\mathrm{SA} 2}=14.3\right)$ than for DFNLC $\left(\delta \varepsilon_{\mathrm{Sd}-\mathrm{f}}=2.2\right)$, (b) DFNLC and base mixture in HG cell. Dielectric strength of L-mode visible in HG cell is higher for base mixture $\left(\delta \varepsilon_{\mathrm{L}}=6.6\right)$ than for DFNLC $\left(\delta \varepsilon_{\mathrm{Ld}-\mathrm{f}}=4.0\right)$.
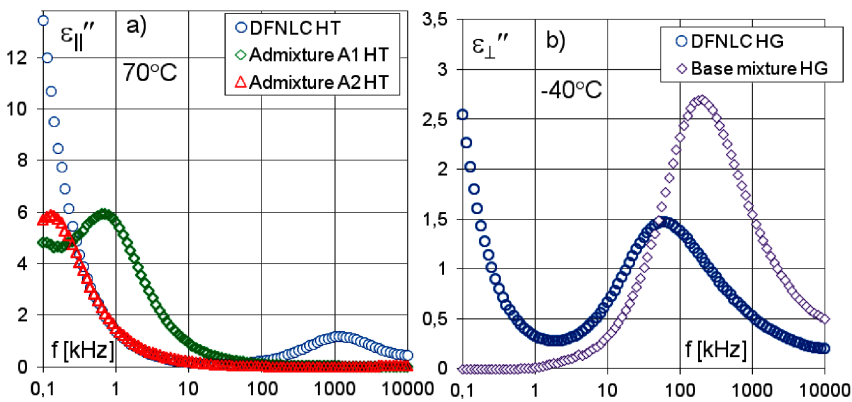

Fig. 6. bsorption of imaginary part of electric permittivity $\varepsilon^{\prime \prime}$ collected for: (a) DFNLC and admixtures in HT cell, (b) DFNLC and base mixture in HG cell.

components (base mixture and admixtures). It can be clear if we remember that base mixture is diluted by molecules of admixture and vice versa and thus dielectric strength should be weakened in final DFNLC mixture. S-rotation is related to large molecules of admixtures while L-rotation is related to small molecules of parent W1832 mixture.

In Fig. 7 the results of relaxation frequencies $\left(f_{R}\right)$ Sand L-modes are shown. To obtain the relaxation fre-

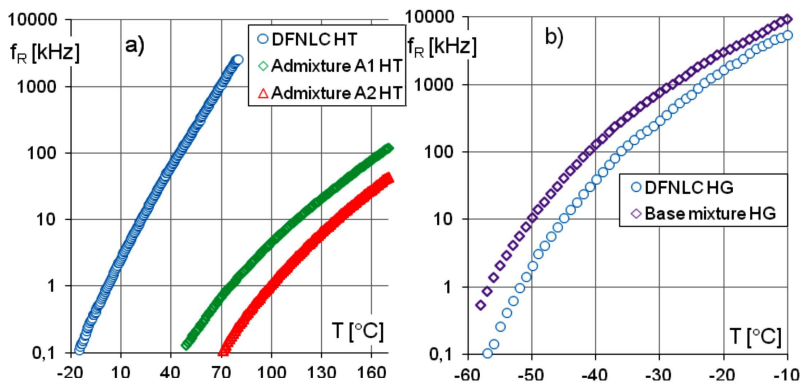

Fig. 7. Relaxation frequencies for: (a) the S-mode and (b) the L-mode in logarithmic scale. quencies $f_{\mathrm{R}}$ the special calculation procedure was used. The calculation procedure was presented earlier [8]. Easily visible rotation around short molecular axis (S-mode) in the admixtures occurs in the whole temperature range of nematic phases (Fig. 7a). The same mode in DFNLC mixture can be detectable from $80^{\circ} \mathrm{C}$ to almost $-20^{\circ} \mathrm{C}$. Relaxation frequency is about $2.5 \mathrm{MHz}$ at $80^{\circ} \mathrm{C}$ and decreases to $0.1 \mathrm{kHz}$ at $-20^{\circ} \mathrm{C}$. The similar behaviour can be observed in the admixtures (for $\mathrm{A} 1$ at $170^{\circ} \mathrm{C}$ $f_{\mathrm{R}}=100 \mathrm{kHz}$, at $50{ }^{\circ} \mathrm{C} f_{\mathrm{R}}=0.1 \mathrm{kHz}$, for $\mathrm{A} 2$ at $170^{\circ} \mathrm{C}$ $f_{\mathrm{R}}=40 \mathrm{kHz}$, at $70^{\circ} \mathrm{C} f_{\mathrm{R}}=0.1 \mathrm{kHz}$ ). We can suppose that the relaxation frequency in the admixtures in higher temperature range $\left(>170^{\circ} \mathrm{C}\right)$ should be higher than $1 \mathrm{MHz}$. S-molecular motions are related to molecules with large dipole moment $\left(\mu_{\|}\right)$parallel to molecules. In final mixture only four-ring molecules of admixtures show such dipole moments. S-mode is only visible in homeotropically oriented sample. Rotation around short molecular axis is slower in pure admixtures ( 1 and A2) than when admixtures are built into DFNLC. For example for the same temperature $\left(70^{\circ} \mathrm{C}\right)$ where $\mathrm{W} 1832$ and admixtures show nematic phases, relaxation frequencies in admixtures A1 and A2 $(0.63 \mathrm{kHz}, 0.1 \mathrm{kHz}$, respectively) are more than three orders lower than relaxation in DFNLC mixture $(1000.2 \mathrm{kHz})$. This effect is related to the fact that heavy four-ring molecules are in W1832 diluted and their relaxation frequency is higher in diluted state.

Calculations relating to the L-mode show that relaxation frequency versus temperature for both: DFNLC and the base mixtures have got a similar shape (Fig. 7b). The relaxation frequency decreases when the temperature decreases. It is worth to underline that the L-mode clearly occurs below $-10^{\circ} \mathrm{C}$ where relaxation frequency is around $10 \mathrm{MHz}$. For L-mode one can notice the opposite effect in comparison with S-mode: L-mode is slower (for the same temperature) while S-mode is faster in DFNLC mixture than in base mixture and admixtures, respectively. Such behaviour can be explained as a result of

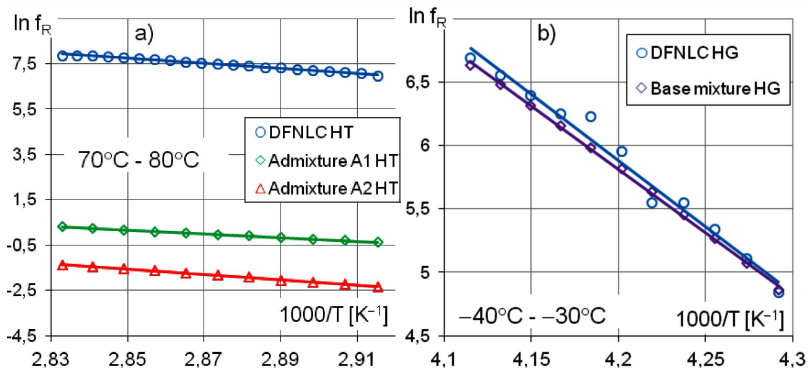

Fig. 8. The Arrhenius plots for: (a) DFNLC and admixtures in HT cell. Activation barrier of S-mode in HT cell is higher for admixture $2\left(\Delta E_{\mathrm{SA} 2}=98.85 \mathrm{~kJ} / \mathrm{mol}\right)$ than for DFNLC and A1 $\left(\Delta E_{\mathrm{Sd}-\mathrm{f}}=92.57, \Delta E_{\mathrm{SA} 1}=\right.$ 67.54), (b) DFNLC and base mixture in HG cell. Activation barrier of L-mode is comparable in HG cell for $\operatorname{DFNLC}\left(\Delta E_{\mathrm{Ld}-\mathrm{f}}=85.98 \mathrm{~kJ} / \mathrm{mol}\right)$ and base mixture $\left(\Delta E_{\mathrm{LB}}=82.92 \mathrm{~kJ} / \mathrm{mol}\right)$. 
interaction between heavy four-ring molecules of admixtures with small molecules constituting the base mixture.

How the preparation of DFNLC influences on the activation barriers. To give the answer for such question Arrhenius plots for S- and L-modes were prepared and are presented in Fig. 8. Both molecular relaxations are thermally activated and thus plots presented in Fig. 7 should be linear. Due to the fact that temperature range of investigated nematic phases is rather wide it is difficult to fit one straight line for the whole temperature range. We decided to divide the Arrhenius plots into narrower temperature intervals $\left(10^{\circ} \mathrm{C}\right.$ each $)$.

In Fig. 8a there are presented results of S-mode from $70^{\circ} \mathrm{C}$ to $80^{\circ} \mathrm{C}$. In this temperature range the relaxation frequency of S-mode can be easily determined for DFNLC and the admixtures 1 and 2 in HT cell. Furthermore the relaxation frequency dependence of the temperature is linear.

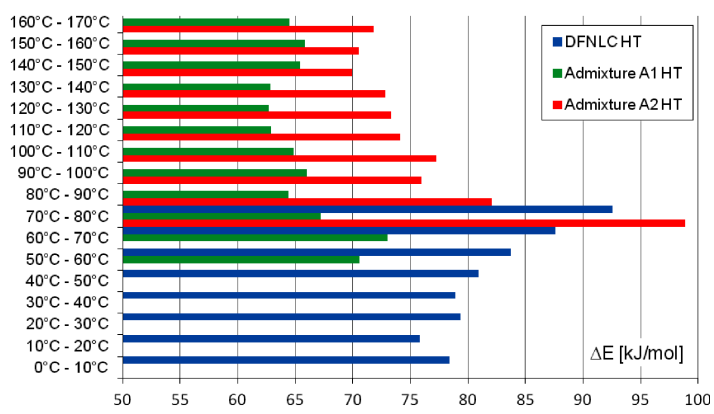

Fig. 9. Activation barriers in HT cell for S-mode observed in: admixtures 1 and A2 and final DFNLC mixture (W1832). Temperature range is divided into $10^{\circ} \mathrm{C}$ intervals.

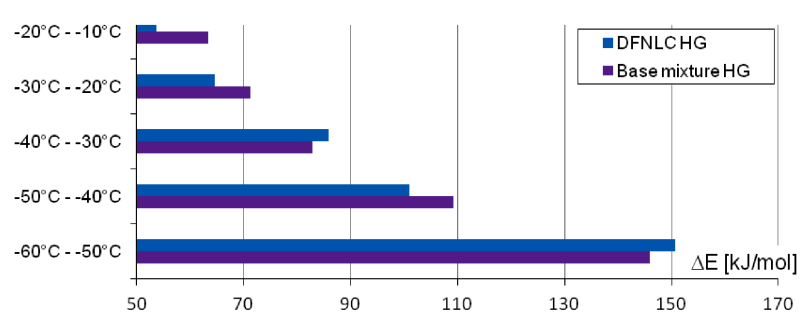

Fig. 10. Activation barriers in HG cell for L-mode observed in: base mixture W1832 and final DFNLC mixture (W1832A). Temperature range is divided into $10^{\circ} \mathrm{C}$ intervals.

The results for whole temperature range are demonstrated in $10^{\circ} \mathrm{C}$ intervals (Fig. 9). In all cases the activation barrier $\Delta E$ of $\mathrm{S}$-mode for the admixture 2 is higher than for A1. The reason of that is larger molecular weight of molecules consisting A2. However $\Delta E$ in A2 is comparable in DFNLC. The Arrhenius plots to determine activation barrier of L-mode observed in the base mixture and DFNLC are shown in Fig. 8b (for temperature interval: $\left.(-40)-(-30)^{\circ} \mathrm{C}\right)$. Creation procedure of
DFNLC mixture slightly modifies the activation barrier of L-mode for the molecules building DFNLC and the base mixture. Activation barrier drops with the increasing temperature. Results of activation barriers for all temperature intervals are plotted in Fig. 10.

\section{Conclusions}

The main goal of this paper was to show that the dielectric spectroscopy is a very powerful tool for investigation of DFNLC mixtures as well as mixtures and components creating DFNLC mixtures. We can split components into two categories. The first one is the base mixture with the negative dielectric anisotropy $(\Delta \varepsilon<0)$. The second one is admixture with the positive dielectric anisotropy $(\Delta \varepsilon>0)$. To create DFNLC we should mix the base mixture and admixture in sufficient quantity. The molecules with perpendicular dipole moments, constituting the base mixture, are responsible also for rotation around long molecular axis in final DFNLC mixture. Relaxation frequency of L-mode in the whole temperature range in both: base and DFNLC mixtures are comparable (Fig. 7b). Relaxation frequencies, corresponding to the molecular rotations around the short axes, observed in DFNLC, are the same as those measured for neat substances. However, at the same temperature $f_{\mathrm{R}}$ is shifted to much higher value (Fig. 7a) due to different surrounding created by small molecules in the base mixture. Additionally a small difference in the molecular weight and dimensions of both molecules ( 1 and A2) causes that only one relaxation process is observed in the final DFNLC mixture. Relaxation frequencies of S-mode influence on cross-over frequency in the final DFNLC mixture.

TABLE II

Comparative table of dielectric properties of the base mixture, admixtures and DFNLC mixture.

\begin{tabular}{|c|c|c|c|}
\hline Mixture: & $\begin{array}{l}\text { Base } \\
\text { mixture }\end{array}$ & dmixtures & $\begin{array}{l}\text { DFNLC } \\
\text { mixture }\end{array}$ \\
\hline $\begin{array}{l}\text { dielectric } \\
\text { anisotropy }\end{array}$ & $\begin{array}{l}\text { negative } \\
(\Delta \varepsilon<0)\end{array}$ & $\begin{array}{l}\text { positive } \\
(\Delta \varepsilon>0)\end{array}$ & $\begin{array}{l}\text { positive } \\
(\Delta \varepsilon>0) \\
\text { and negative } \\
(\Delta \varepsilon<0)\end{array}$ \\
\hline rotation & $\begin{array}{l}\text { around long } \\
\text { (L-mode) } \\
\text { molecular } \\
\text { axis }\end{array}$ & $\begin{array}{l}\text { around short } \\
\text { (S-mode) } \\
\text { molecular } \\
\text { axis }\end{array}$ & $\begin{array}{l}\text { around short } \\
\text { (S-mode) } \\
\text { and long } \\
\text { (L-mode) } \\
\text { molecular } \\
\text { axes }\end{array}$ \\
\hline $\begin{array}{l}\text { dipole } \\
\text { moment }\end{array}$ & $\begin{array}{l}\text { transverse } \\
\left(\mu_{\perp}\right)\end{array}$ & $\begin{array}{l}\text { longitudinal } \\
\left(\mu_{\|}\right)\end{array}$ & $\begin{array}{l}\text { longitudinal } \\
\left(\mu_{\|}\right) \text {and } \\
\text { transverse } \\
\left(\mu_{\perp}\right)\end{array}$ \\
\hline $\begin{array}{l}\text { relaxation } \\
\text { frequency of } \\
\text { S-mode }\end{array}$ & not present & low & $\begin{array}{l}\text { higher than } \\
\text { in admixtures }\end{array}$ \\
\hline $\begin{array}{l}\text { relaxation } \\
\text { frequency of } \\
\text { L-mode }\end{array}$ & high & not present & $\begin{array}{l}\text { a little lower } \\
\text { than in base } \\
\text { mixture }\end{array}$ \\
\hline
\end{tabular}


Activation barriers of the L-mode in the base mixture and final DFNLC mixture (1832 A) are comparable. On the other hand, activation barriers of the S-mode change can be seen in admixtures 1, 2 and final DFNLC mixture different activation barriers of S-mode.

All important information from the dielectric spectroscopy point of view is collected in Table II.

\section{Acknowledgments}

This work was supported by Polish Ministry of Sciences and Higher Education project no. 0144/RIT00: Tunable liquid crystal filters for $\mathrm{THz}$ and $\mathrm{GHz}$ range.

\section{References}

[1] M. Schadt, Appl. Phys. Lett. 41, 697 (1982).

[2] M. Schadt, Mol. Cryst. Liq. Cryst. 89, 77 (1982).

[3] H.Q. Xianyu, S.T. Wu, C.L. Lin, Liq. Cryst. 36, 717 (2009).

[4] P. Kumar, S.-W. Kang, S.H. Lee, Opt. Mater. Expr. 2, 1121 (2012).
[5] X. Liang, Y.Q. Lu, Y.H. Wu, F. Du, H.Y. Wang, S.T. Wu, Jpn. J. Appl. Phys. 44, 1292 (2005).

[6] J. Czub, R. Dabrowski, J. Dziaduszek, S. Urban, Phase Transit. 82, 485 (2009).

[7] J. Czub, R. Dabrowski, S. Urban, Phase Transit. 80, 631 (2007).

[8] P. Perkowski, M. Mrukiewicz, K. Garbat, M. Laska, U. Chodorow, W. Piecek, R. Dabrowski, J. Parka, Liq. Cryst. 39, 1237 (2012).

[9] P. Perkowski, M. Mrukiewicz, M. Laska, K. Garbat, W. Piecek, R. Dabrowski, Phase Transit. 86, 113 (2013).

[10] R. Dabrowski, J. Dziaduszek, K. Garbat, M. Filipowicz, S. Urban, S. Gauza, G. Sasnouski, Liq. Cryst. 37, 1529 (2010).

[11] P. Perkowski, D. Lada, K. Ogrodnik, J. Rutkowska, W. Piecek, Z. Raszewski, Opto-Electron. Rev. 16, 271 (2008).

[12] P. Perkowski, Opto-Electron. Rev. 17, 180 (2009).

[13] P. Perkowski, Opto-Electron. Rev. 20, 79 (2012). 